\title{
Increased Prevalence of Autoimmunity and Connective Tissue Diseases in Sickle Cell Disease
}

\author{
Norris Igbineweka ${ }^{1,2}$, Deepika S Darbari ${ }^{3,6}$, Emma R Drasar ${ }^{1,7}$, Sophia Steer ${ }^{5}$ and Swee Lay Thein ${ }^{1,3,4^{*}}$ \\ ${ }^{1}$ Faculty of Life Sciences and Medicine, Molecular Hematology, Division of Cancer Studies, King's College London, SE5 9NU, UK \\ ${ }^{2}$ Department of Haematology, Brighton and Sussex NHS Trust, Brighton, BN2 5BE, UK \\ ${ }^{3} \mathrm{NIH}$, National Heart, Lung, and Blood Institute, Sickle Cell Branch, Bethesda, MD 20892, USA \\ ${ }^{4}$ Department of Haematological Medicine, King's College Hospital NHS Foundation Trust, Denmark Hill, London SE5 9RS, UK \\ ${ }^{5}$ Department of Rheumatology, King's College Hospital NHS Foundation Trust, Denmark Hill, London SE5 9RS, UK \\ ${ }^{6}$ Division of Hematology, Children's National Medical Center, Washington, DC 20010, USA \\ ${ }^{7}$ Department of Pathology, The Whittington Hospital NHS Trust, Magdala Avenue, London N19 5NF, UK
}

\begin{abstract}
Connective tissue disease (CTD) and sickle cell disease (SCD) are diverse group of disorders; however, both of these diseases are characterized by underlying chronic inflammation. CTD is perceived to have a higher incidence and to affect the disease severity in SCD.
\end{abstract}

Objectives: We seek to describe prevalence of autoimmunity and CTD and itsimpact on SCD disease severity as this is not well described in the literature.

Methods: We retrospectively reviewed the medical records of 722 patients with SCD, seen over an 11 year period followed at a tertiary care hospital in London, UK. During the last 2 years of the study, number of hospitalizations and length of hospital stay were compared in patients with SCD with and without CTD.

Results: In the study cohort, hemoglobin SS was the most common genotype ( $n=451 ; 62 \%)$ and $411(57 \%)$ were female. Twenty-three patients (3.1\% had documented evidence of CTD, with rheumatoid arthritis $(n=14 ; 2 \%)$ and systemic lupus erythematosus $(n=2 ; 0.3 \%)$ being the most common. Antinuclear antibody was present in 108 $(15 \%)$ of the patients and anti-smooth muscle antibody was present in $60(8 \%)$. The mean number of hospitalizations $(1.9 \pm 2.7$ vs. $1.5 \pm 2.7)$ and mean length of hospital stay ( 6 days \pm 4.1 vs. 7 days \pm 11.4$)$ were not different between those with or without autoimmunity and/or CTD. Avascular necrosis was the most common non-CTD musculoskeletal complication, affecting $72(10 \%)$ patients.

Conclusion: Our study suggests that positive autoimmune serology and CTD were more common in SCD compared to non-SCD population of similar ethnic background; however, presence of CTD does not appear to affect the SCD severity. The high frequency of CTD and overlapping of clinical symptoms suggest a need for diagnostic vigilance in diagnosing CTD in patients with SCD.

Keywords: Connective tissue disease; Sickle cell disease

\section{Introduction}

Sickle cell disease (SCD) is an inherited condition caused by a mutation at the $\beta 6$ position of hemoglobin $(\mathrm{Hb})(\beta 6 \mathrm{Glu} \rightarrow \mathrm{Val})$. The disease is characterised by chronic hemolytic anemia and episodes of acute illness caused by vaso-occlusion leading eventually to progressive organ damage. It is a multisystem disease underlined by a chronic inflammatory state and vasculopathy, pathological events triggered by the polymerization of the intraerythrocytic deoxyHbS. Involvement of musculoskeletal system is common in patients with SCD. While painful vaso-occlusive crises (VOC) are considered the hallmark musculoskeletal manifestation of SCD, other complications involving musculoskeletal system such as connective tissue disorders (CTD) also exist and require a high index of suspicion for timely diagnosis as manifestations may be similar and overlap in both diseases $[1,2]$.

Connective tissue diseases (CTDs) are a heterogeneous group of systemic diseases some of which have immune dysregulation as its etiology, including rheumatoid arthritis (RA) and systemic lupus erythematosus (SLE). CTD is perceived to have a higher incidence in patients with SCD, supported by several studies which demonstrate high levels of autoimmunity amongst patients with SCD $[3,4]$. While positive autoimmune status is not always indicative of clinical disease, a prospective study of 88 patients identified high titres of autoantibodies in patients with SCD compared to controls without SCD [3]. Reports of the presence of CTDs in patients with SCD are mostly anecdotal case studies [1,5-7]. Further, diagnostic uncertainty remains over defining the onset of CTD, for example, differentiating a flare-up of RA from an acute VOC in patients with SCD.

It is unclear as to what extent the co-existence of CTD and SCD influences the clinical severity of each other. There is also debate to what effect CTD drug treatment, such as steroids and immunosuppressants, may have on SCD. Consequently, there remain unresolved issues concerning the prevalence, diagnosis and therapy of CTD's in patients with SCD.

This study aims to raise awareness amongst clinicians providing

*Corresponding author: Swee Lay Thein, National Heart, Lung, and Blood Institute, National Institute of Health, Building 10-CRC/5E-5142, 10 Center Drive Bethesda, MD 20892, USA, Tel: +1 301-435-2345; Fax: +1 301-451-7091; E-mail: sl.thein@nih.gov

Received February 16, 2016; Accepted February 22, 2016; Published February 29, 2016

Citation: Igbineweka N, Darbari DS, Drasar ER, Steer S, Thein SL (2016) Increased Prevalence of Autoimmunity and Connective Tissue Diseases in Sickle Cell Disease. J Gen Pract 4: 236. doi: 10.4172/2329-9126.1000236

Copyright: $\odot 2016$ Igbineweka N. This is an open-access article distributed unde the terms of the Creative Commons Attribution License, which permits unrestricted use, distribution, and reproduction in any medium, provided the original author and source are credited. 
Citation: Igbineweka N, Darbari DS, Drasar ER, Steer S, Thein SL (2016) Increased Prevalence of Autoimmunity and Connective Tissue Diseases in Sickle Cell Disease. J Gen Pract 4: 236. doi: 10.4172/2329-9126.1000236

Page 2 of 4

care to SCD patients of the overlapping clinical manifestations of SCD and CTD, which could lead to delay in diagnosis and treatment. We conducted a review of our large, well-defined adult sickle cohort in London, UK, to ascertain the incidence of co-existing CTD, and explored the clinical severity of both groups of conditions using biochemical and clinical data over an eleven-year period. We also reviewed other causes of musculoskeletal involvement in the study population which may or may not be directly related to SCD.

\section{Methods}

\section{Patient population}

The cohort included adolescents and adult patients ( $\geq 16$ years) attending the Sickle Cell Center in King's College Hospital, London. The 11 year study period was between 1 January 1999 to 31 December 2010 , or to the last patient record or death. Interrogation of the data was performed on two databases: the sickle cell database (from which the register of patients with $\mathrm{SCD}$ at $\mathrm{KCH}$ were derived) and the Electronic Patient Records (EPR) (EPR iSOFT Group, Sydney, Australia).

Serological and clinical data were extracted from EPR for each patient on the sickle cell database. Serological evidence included autoimmune data such as anti-nuclear antibodies (ANA), and rheumatoid factor (RhF). Positive autoimmune status was defined as having $\geq 1$ episode of sero-positivity between years 1999-2010 and included all titres of sero-positivity. These laboratory tests are routinely performed as baseline tests amongst SCD patients at KCH. Erythrocyte sedimentation rate (ESR) and C-reactive protein (CRP) were not included in the analysis as these acute phase reactants are unreliable for analysis. We also documented the clinical details relating to the CTD if present, through relevant clinic letters, rheumatology/dermatology referrals and discharge summaries. Diagnostic criteria for CTD were according to the American College for Rheumatology. For the latter two years of our study period, patients with $\mathrm{HbSS}$ or $\mathrm{HbS} \beta 0$ (considered as sickle cell anaemia, SCA) and CTD were compared against two markers of disease severity: number of hospital admissions for pain related to SCD, and length of hospital stay.

\section{Statistical Analysis}

Data was summarised in Excel 2010 (Microsoft) and analyses were performed in SPSS version 20 (IBM). Binary variables were merged into larger sub-groups to enable data analysis. Continuous variables were summarized using mean values and percentages. The Student's $t$ test was used to assess significant differences between the mean values of different groups.

\section{Results}

During the 11 year study period, data were available for 722 patients, who were all of African or African-Caribbean descent (Table 1). The cohort included 411 women (57\%) and 311 men (43\%) with 451 (62\%) HbSS, 225 (31\%) HbSC, 33 (5\%) HbS $\beta$ + thalassemia, and 13 (2\%) $\mathrm{HbS} \beta 0$ thalassemia patients. At of the time of analysis, age range of patients was between 16 to 86 years, with mean 36, and median 34 years.

\section{Prevalence of musculoskeletal disease}

135 patients (18.7\%) had evidence of $\geq 1$ musculoskeletal disease(s) (Table 1). The most common cause of musculoskeletal involvement was avascular necrosis (AVN) of the hip affecting 72 patients (10\%) while the most common CTD was RA affecting 14 patients (1.9\%).

\begin{tabular}{|c|c|}
\hline & $\mathbf{n}$ \\
\hline Total Group & 722 \\
\hline M (\%) & $\begin{array}{l}311 \\
(43)\end{array}$ \\
\hline $\mathrm{F}(\%)$ & $\begin{array}{l}411 \\
(57)\end{array}$ \\
\hline Age Range (years) & $16-86$ \\
\hline Mean Age (years) & 36 \\
\hline \multicolumn{2}{|l|}{ Genotypes } \\
\hline HbSS (\%) & $\begin{array}{l}451 \\
(61)\end{array}$ \\
\hline $\mathrm{HbSC}(\%)$ & $\begin{array}{l}225 \\
(31)\end{array}$ \\
\hline $\mathrm{HbSB}^{+}(\%)$ & $33(5)$ \\
\hline $\mathrm{HbSB}^{0}(\%)$ & $13(2)$ \\
\hline \multicolumn{2}{|l|}{ Musculoskeletal Disease } \\
\hline Avascular Necrosis (\%) & $72(10)$ \\
\hline Osteoarthritis (\%) & $22(3)$ \\
\hline Osteomyelitis (\%) & $19(2.6)$ \\
\hline Unspecified Inflammatory Disease* (\%) & $16(2.1)$ \\
\hline Rheumatoid Arthritis (\%) & $14(1.9)$ \\
\hline Gout (\%) & $9(1.2)$ \\
\hline Septic Arthritis (\%) & $9(1.2)$ \\
\hline Sarcoid (\%) & $3(0.4)$ \\
\hline Adhesive Capsulitis (\%) & $2(0.3)$ \\
\hline Carpal Tunnel Syndrome (\%) & $2(0.3)$ \\
\hline Osteoporosis (\%) & $2(0.3)$ \\
\hline Systemic Lupus Erythematosus (\%) & $2(0.3)$ \\
\hline Anti-Phospholipid Syndrome (\%) & $1(0.1)$ \\
\hline Discoid Lupus Erythematosus (\%) & $1(0.1)$ \\
\hline Haemoarthrosis (\%) & $1(0.1)$ \\
\hline Lateral Epicondylitis (\%) & $1(0.1)$ \\
\hline Mixed Connective Tissue Disorder (\%) & $1(0.1)$ \\
\hline Raynaud's Phenomenon (\%) & $1(0.1)$ \\
\hline Scoliosis (\%) & $1(0.1)$ \\
\hline Stenosing Tenosynovitis (\%) & $1(0.1)$ \\
\hline Ulnar Nerve Entrapment (\%) & $1(0.1)$ \\
\hline \multicolumn{2}{|c|}{$\begin{array}{l}\text { *Unspecified Inflammatory Disease includes unclear/unspecified diagnoses of } \\
\text { inflammatory disease e.g. synovitis, tendonitis, bursitis of particular regions of } \\
\text { body. }\end{array}$} \\
\hline
\end{tabular}

Table 1: Prevalence of musculoskeletal disease, demographic and genotypic information of sickle cell disease study group.

\section{Prevalence of positive serology and connective tissue disease}

Overall 33\% ( $n=236)$ of patients had positive autoimmune status. Positive anti-nuclear antibodies (ANA) were the most prevalent form of autoimmunity $(\mathrm{n}=108 ; 15 \%)$ followed by smooth muscle antibody $(n=60 ; 8.3 \%)$, gastric parietal antibody $(n=30 ; 4.2 \%)$ and rheumatoid factor $(\mathrm{n}=18 ; 2.5 \%)$ (Figure 1$)$. In the ANA positive group two thirds were female with a mean age of 40 years compared with 34.8 years in those with ANA negative serology. Similar trends of female predominance and older age were observed for other positive serology. Presence of positive serology alone was not indicative of CTD. For example, the prevalence of rheumatoid factor positivity was $2.5 \%$ while $1.9 \%$ had clinical RA. Similarly, anti-double stranded DNA antibodies were positive in 5 patients but only 2 of the 5 patients had clinical manifestations of SLE.

Twenty-three patients (3.1\%) had documented evidence of CTD (Table 1). Nineteen of the 23 patients with CTD were women and the average age for those with CTD was 41.1 years compared to 35.4 years 


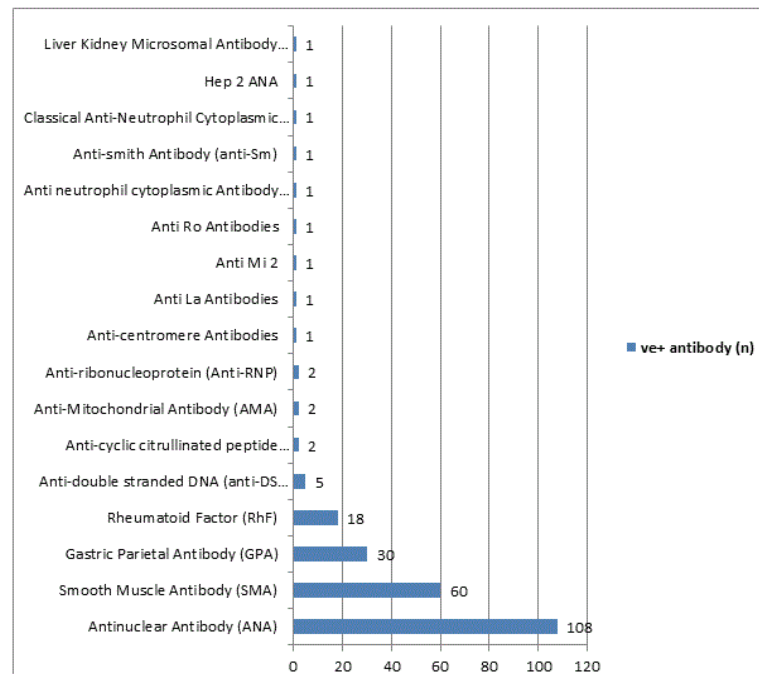

Figure 1: Positive autoimmune serology in patients with sickle cell disease.

in those without CTD. The HbSS group had the highest prevalence of CTD amongst genotypes accounting for 15 patients followed by HbSC genotype with 6 patients which may be a reflection of the distribution sickle cell group overall.

\section{Connective tissue disease, number of hospital admissions and length of hospital stay}

During the last two years of the study (2008-2010), SCA patients with any positive autoimmune serology and/or CTD $(n=102)$ had a mean of $1.9( \pm 2.7)$ admissions compared to a mean of $1.5( \pm 2.7)$ admissions in those without autoimmunity and/or CTD $(n=210)$. The mean length of hospital stay in admitted patients for all SCD-related complications was 6 days $( \pm 4.1)$ in those with autoimmunity and/or CTD $(\mathrm{n}=46)$ compared to 7 days $( \pm 11.4)$ in those without $(\mathrm{n}=108)$ (Figure 2). Both of these analyses were not statistically significant.

\section{Non-CTD musculoskeletal manifestations}

AVN was the most prevalent musculoskeletal disease in the SCD cohort involving 72 patients (10\%) as evidenced by both clinic letters and radiological report. The mean age for the 72 patients (35 female and 37 male) was 40 years, and they included 51 (71\%) HbSS, $14(19 \%)$ $\mathrm{HbSC}, 4(6 \%) \mathrm{HbS} \beta$ + thalassemia, and $3(4 \%) \mathrm{HbS} \beta 0$ thalassemia. Other causes of musculoskeletal involvement included osteoarthritis (OA) in 22 patients (3\%) with average age of 51 years and osteomyelitis in 19 patients. Nine patients (1.2\%) had clinical gout however hyperuricemia was present in 118 patients (16.3\%).

\section{Discussion}

This retrospective study showed that $3.1 \%$ of our SCD cohort had CTD, with RA, sarcoid and SLE being the most prevalent. RA appears to be more prevalent in our patient cohort compared to that previously reported (2\% vs. $0.29 \%)$ in the Manchester (UK) based cohort study of 1046 black Caribbeans [8]. Other studies have also demonstrated a lower prevalence of RA in blacks particularly in rural African populations $[9,10]$. Urbanisation may be an influential factor in the development of RA in blacks; a study in Soweto showed that the prevalence of RA in black South Africans living in urban areas is comparable to that in white Europeans [11]. The prevalence for SLE amongst all races in the

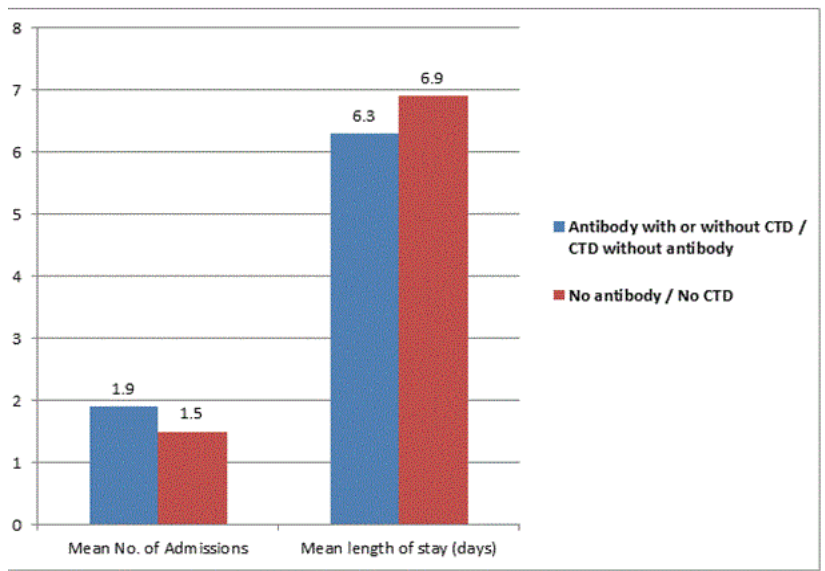

Figure 2: Autoimmune/connective tissue disease status vs. mean number of hospital admissions and length of stay among patients with sickle cell anemia.

UK is described as 26.2 per 100,000 [12]. Amongst African-Caribbean populations in the UK, it is at a higher prevalence of 159.4 per 100,000 $(0.16 \%)$. In our study, the prevalence of SLE was $0.3 \%$, significantly higher than in the non-SCD population suggesting possibility of SCD increasing the prevalence of CTDs. All 5 patients with SCD and SLE had ds-DNA antibodies and were assessed by a rheumatologist; it should be noted that autoantibodies to DNA develop between 2.7 to 9.3 years before clinical presentation and diagnosis of lupus [13]. Sarcoidosis also appeared to be more prevalent in our SCD population (0.4\%) compared to non-SCD African-Caribbeans [14].

Our study showed that women with SCD were 10 times more likely to have RA than men with SCD which is significantly greater than the reported gender differences in the general population where women were 3 times more likely to develop RA compared to men [15]. SCD could potentially have an increased risk of developing CTD similar to that speculated for patients with beta-thalassemia trait and its association with higher rates of RA $[1,16]$. However, larger longitudinal population studies would be needed to characterize these associations between these hemoglobinopathies and the development of CTD. In addition to clinical and epidemiological considerations, one should also explore if SCD provides an immune-stimulatory milieu towards the development of CTD [17].

ANA positive serology was present in $15 \%$ of our patients in keeping with the previously reported figures of autoimmunity $[3,4,18]$. Additionally, $8.3 \%$ of our patients had SMA positive serology. This high prevalence of autoantibody reactivity adds to the diagnostic challenge in differentiating the onset of CTD in SCD. Additionally, clinical similarities in clinical presentation of CTDs and SCD can further lead to diagnostic imprecision and diagnostic delay $[6,19]$ which can have a huge impact on diseases like RA and SLE where early intervention with disease modifying anti-rheumatic drugs (DMARD's) is crucial for prevention of disease progression.

There were no statistically significant differences in number of admissions or length of hospital stay amongst SCD patients with or without autoimmunity and/or CTD. This is similar to conclusions by Michel et al. [1] suggesting that CTD-related clinical manifestations and outcome were not particularly severe in patients with SCD. However, these conclusions have limitations as both of these studies utilized hospital admission as an outcome and no other clinically significant 
Citation: Igbineweka N, Darbari DS, Drasar ER, Steer S, Thein SL (2016) Increased Prevalence of Autoimmunity and Connective Tissue Diseases in Sickle Cell Disease. J Gen Pract 4: 236. doi: 10.4172/2329-9126.1000236

end points such as severe SCD phenotypes e.g. pulmonary hypertension or noting specifically the use of steroids $+/$ - methotrexate for CTD which has been reported to increase disease severity in $43 \%$ of patients with associated SCD utilizing a scoring system [1]. Consequently, the effects of clinical severity in CTD associated with SCD are not entirely elucidated and require further research.

Among non-CTD musculoskeletal manifestations, AVN was the most common affecting $10 \%$ of the population. This is consistent with the reported figures of AVN prevalence figures of 4-50\% [1,20,21]. The second most common non-CTD musculoskeletal manifestation was OA with a prevalence of $3 \%$, similar to previously figures [22]. The average age for OA in SCD was younger at 36 years compared to $>50$ years in non-SCD population $[23,24]$. There were also high proportions of patients with hyperuricemia (16.3\% of SCD patients) but little clinical correlation to the development of gout (1.2\% of SCD patients). Twenty-five percent of men with SCD in our study were hyperuricemic. This may highlight the need for cardiovascular risk assessment within this group as hyperuricemia is increasingly being shown to be a risk factor for cardio-reno-vascular system [25].

Several limitations relate to the fact that this study had a retrospective design. Prevalence comparison with other epidemiological data should be taken with caution as different studies may employ different diagnostic and inclusion criteria. The possibility of diagnostic uncertainty relating to CTD, as highlighted by the significant number of "unspecified inflammatory disease" in our cohort, may have led to under-diagnosis of CTD. There may also be an opportunity for diagnostic delay, although this was not formally assessed in our study group. Nevertheless, our study demonstrates that the prevalence of CTD was higher in our SCD population than expected emphasizing the need for diagnostic vigilance in considering CTD in the patients with SCD. There were no statistically significant differences in number of admissions or hospital stay between SCD patients with autoimmunity and/or CTD compared to those without. However, further larger studies are needed assessing various other clinical severity end points in order to elucidate clinical outcomes of these patients.

\section{References}

1. Michel M, Habibi A, Godeau B, Bachir D, Lahary A, et al. (2008) Characteristics and outcome of connective tissue diseases in patients with sickle-cell disease: report of 30 cases. Semin Arthritis Rheum 38: 228-240.

2. Jean-Baptiste G, De Ceulaer K (2000) Osteoarticular disorders of haematological origin. Baillieres Best Pract Res Clin Rheumatol 14: 307-323.

3. Toly-Ndour C, Rouquette AM, Obadia S, M'bappe P, Lionnet F, et al. (2011) High titers of autoantibodies in patients with sickle-cell disease. J Rheumatol 38: 302-309.

4. Quismorio FP Jr, Johnson C (1984) Serum autoantibodies in patients with sickle cell anemia. Am J Med Sci 287: 13-15.

5. Nistala K, Murray KJ (2001) Co-existent sickle cell disease and juvenile rheumatoid arthritis. Two cases with delayed diagnosis and severe destructive arthropathy. J Rheumatol 28: 2125-2128.

6. Khalidi NA, Ajmani H, Varga J (2005) Coexisting systemic lupus erythematosus and sickle cell disease: a diagnostic and therapeutic challenge. Journal of clinical rheumatology: practical reports on rheumatic \& musculoskeletal diseases 11: 86-92.
7. Shetty AK, Kumar SR, Gedalia A, Warrier RP (1998) Sickle cell anemia with systemic lupus erythematosus: response to hydroxyurea therapy. J Pediat Hematol Oncol 20: 335-337.

8. MacGregor AJ, Riste LK, Hazes JM, Silman AJ (1994) Low prevalence of rheumatoid arthritis in black-Caribbeans compared with whites in inner city Manchester. Ann Rheum Dis 53: 293-297.

9. Silman AJ, Ollier W, Holligan S, Birrell F, Adebajo A, et al. (1993) Absence of rheumatoid arthritis in a rural Nigerian population. J Rheumatol 20: 618-622.

10. Brighton SW, de la Harpe AL, van Staden DJ, Badenhorst $\mathrm{JH}$, Myers $\mathrm{OL}$ (1988) The prevalence of rheumatoid arthritis in a rural African population. J Rheumatol 15: 405-408.

11. Solomon L, Beighton P, Lawrence JS (1975) Rheumatic disorders in the South African Negro. Part II. Osteo-arthrosis. S Afr Med J 49: 1737-1740.

12. D'Cruz DP, Khamashta MA, Hughes GR (2007) Systemic lupus erythematosus. Lancet 369: 587-596.

13. Arbuckle MR, McClain MT, Rubertone MV, Scofield RH, Dennis GJ, et al (2003) Development of autoantibodies before the clinical onset of systemic lupus erythematosus. N Engl J Med 349: 1526-1533.

14. Rybicki BA, Major M, Popovich J Jr, Maliarik MJ, lannuzzi (1997) Racia differences in sarcoidosis incidence: a 5-year study in a health maintenance organization. American journal of epidemiology 145: 234-241.

15. Oliver JE, Silman AJ (2009) Why are women predisposed to autoimmune rheumatic diseases? Arthritis Res Ther 11: 252.

16. Arman MI, Butun B, Doseyen A, Bircan I, Guven A (1992) Frequency and features of rheumatic findings in thalassaemia minor: a blind controlled study. Br J Rheumatol 31: 197-199.

17. Wilson WA, Hughes GR, Lachmann PJ (1976) Deficiency of factor B of the complement system in sickle cell anaemia. Br Med J 1: 367-369.

18. Baethge BA, Bordelon TR, Mills GM, Bowen LM, Wolf RE, et al. (1990) Antinuclear antibodies in sickle cell disease. Acta Haematol 84: 186-189.

19. Appenzeller S, Fattori A, Saad ST, Costallat LT (2008) Systemic lupus erythematosus in patients with sickle cell disease. Clin Rheumatol 27: 359-364.

20. Hernigou P, Bachir D, Galacteros F (2003) The natural history of symptomatic osteonecrosis in adults with sickle-cell disease. J Bone Joint Surg Am 85-A 500-504.

21. Milner PF, Kraus AP, Sebes JI, Sleeper LA, Dukes KA, et al. (1991) Sickle cell disease as a cause of osteonecrosis of the femoral head. N Engl J Med 325: 1476-1481.

22. Felson DT, Lawrence RC, Dieppe PA, Hirsch R, Helmick CG, et al. (2000) Osteoarthritis: new insights. Part 1: the disease and its risk factors. Ann Intern Med 133: 635-646.

23. Murphy L, Schwartz TA, Helmick CG, Renner JB, Tudor G, et al. (2008) Lifetime risk of symptomatic knee osteoarthritis. Arthritis Rheum 59: 1207-1213.

24. Bijlsma JW, Berenbaum F, Lafeber FP (2011) Osteoarthritis: an update with relevance for clinical practice. Lancet 377: 2115-2126.

25. Stack A, Manolis AJ, Ritz E (2015) Detrimental role of hyperuricemia on the cardio-reno-vascular system. Curr Med Res Opin 31 Suppl 2: 21-26. 